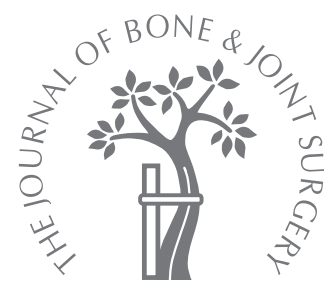

- SPINE

\title{
Dropped-head syndrome resulting from injury to the central spinal cord at the upper cervical level
}

C. L. Rust,

A. C. Ching,

R. A. Hart

From Oregon Health and Science

University, Portland, United States
ㄷ. L. Rust, MD, Resident, Orthopaedic Surgeon A. C. Ching, MD, Assistant Professor

R. A. Hart, MD, Associate Professor, Orthopaedics Residency Director, Spine Fellowship Director Department of Orthopaedics and Rehabilitation Oregon Health and Science University, 3181 SW Sam Jackson Park Road, OP31, Portland, Oregon 97239, USA.

Correspondence should be sent to Professor R. A. Hart; e-mail: hartro@ohsu.edu

(C)2011 British Editorial Society of Bone and Joint Surgery doi:10.1302/0301-620X.93B4. $26107 \$ 2.00$

$J$ Bone Joint Surg $[\mathrm{Br}]$ 2011;93-B:503-6.

Received 19 October 2010

Accepted 6 January 2011

\begin{abstract}
There are many causes of paraspinal muscle weakness which give rise to the dropped-head syndrome. In the upper cervical spine the central portion of the spinal cord innervates the cervical paraspinal muscles. Dropped-head syndrome resulting from injury to the central spinal cord at this level has not previously been described. We report two patients who were treated acutely for this condition. Both presented with weakness in the upper limbs and paraspinal cervical musculature after a fracture of C2. Despite improvement in the strength of the upper limbs, the paraspinal muscle weakness persisted in both patients. One ultimately underwent cervicothoracic fusion to treat her dropped-head syndrome.

While the cause of the dropped-head syndrome cannot be definitively ascribed to the injuries to the spinal cord, this pattern is consistent with the known patho-anatomical mechanisms of both injury to the central spinal cord and dropped-head syndrome.
\end{abstract}

Many causes of dropped-head syndrome have been described including structural abnormalities, such as those resulting from ankylosing spondylitis and post-traumatic or postlaminectomy cervical kyphosis, as well as muscular or neurological abnormalities which produce either increased tone of the flexor muscles of the neck or decreased tone of the extensors. ${ }^{1-4}$ Reported neuromotor causes include myasthenia gravis, Parkinson's disease, poliomyositis, amyotrophic lateral sclerosis and upper cervical myelopathy, all of which produce cervical paraspinal muscle weakness which prevents the patient from maintaining an upright position of the head. ${ }^{5-7}$

Schneider, Cherry and Pantek ${ }^{8}$ described central cord syndrome in 1954 as "disproportionately more motor impairment of the upper than of the lower extremities, bladder dysfunction, usually urinary retention, and varying degrees of sensory loss below the lesion". They went on to describe this pattern of injury as most often being due to a cervical hyperextension injury with buckling of the ligamentum flavum, often "without apparent damage to the bony spine", but also sometimes associated with fracture dislocations or cervical compression fractures. Other authors have extended these observations to include other osseoligamentous injuries as well as different neurological presentations. ${ }^{9-14}$

The most central portions of the motor tracts of the spinal cord in the region of C1-2 supply the cervical paraspinal musculature and start to leave the spinal canal by the third cervical nerve root. ${ }^{15-17}$ Thus, an injury to the central spinal cord above C3 would be expected to cause severe weakness of the cervical paraspinal musculature, potentially extending to the upper and lower limbs. Paraspinal weakness would result in a dropped-head appearance. To our knowledge, dropped-head syndrome has not been reported after an injury of the upper cervical spinal cord.

While central cord syndrome has been previously described in association with fractures of $\mathrm{C} 2,{ }^{10}$ we propose a previously undescribed pattern of central cord syndrome, in which the worst damage is to the most central of the motor tracts at the level of C2, that is those supplying the cervical paraspinal musculature.

We describe two patients with a fracture of C2 who developed dropped-head syndrome. The patients consented to the publication of information concerning their cases.

\section{Case reports}

Case 1. A 59-year-old man suffered a highenergy blow to his head and neck. He presented with a type-II ${ }^{18}$ hangman's fracture of the axis, dissection of an internal carotid artery, a mandibular fracture and a mild closed head injury (Fig. 1). MRI showed an abnormal signal in the region immediately between the C2-3 disc space (Fig. 2). An increased signal in the $\mathrm{C} 2-3$ disc itself, as well as in the posterior 


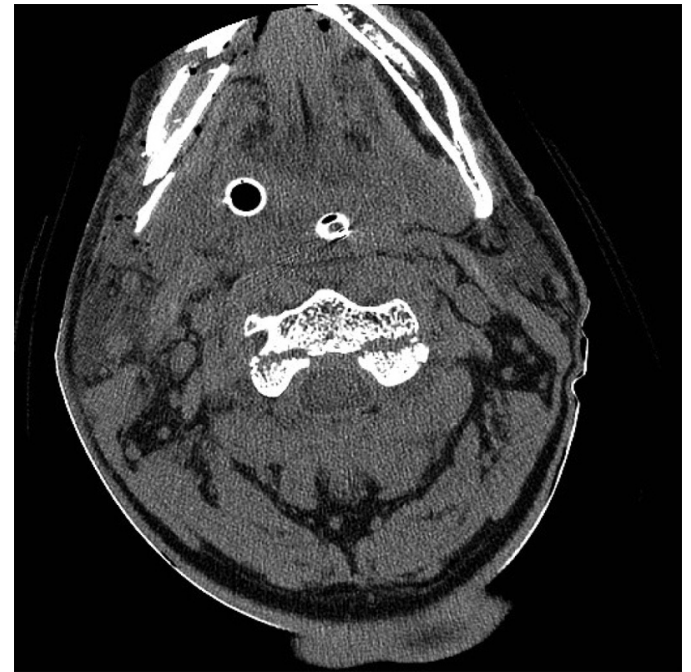

Fig. 1a

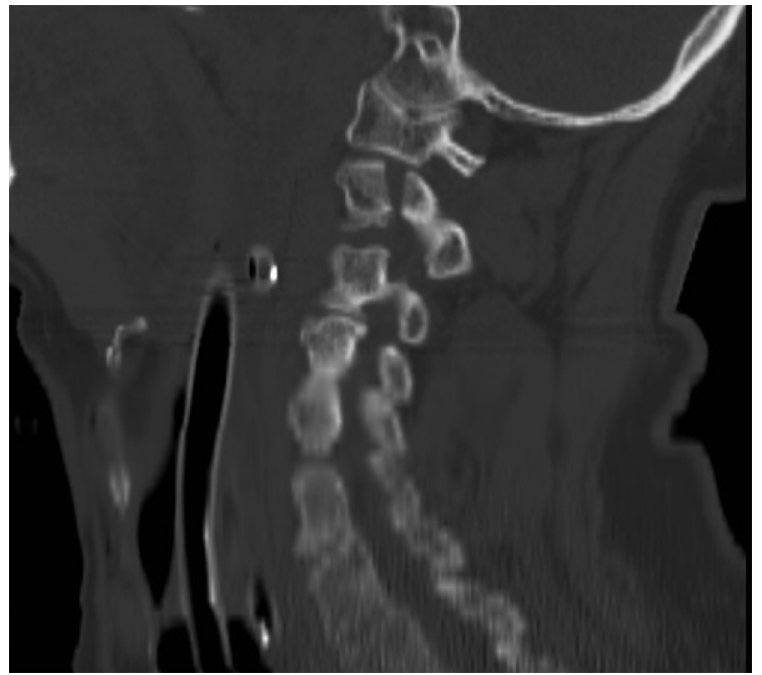

Fig. 1b

Case 1 - Transverse (a) and sagittal (b) CT scans showing a type-II hangman's fracture of C2.

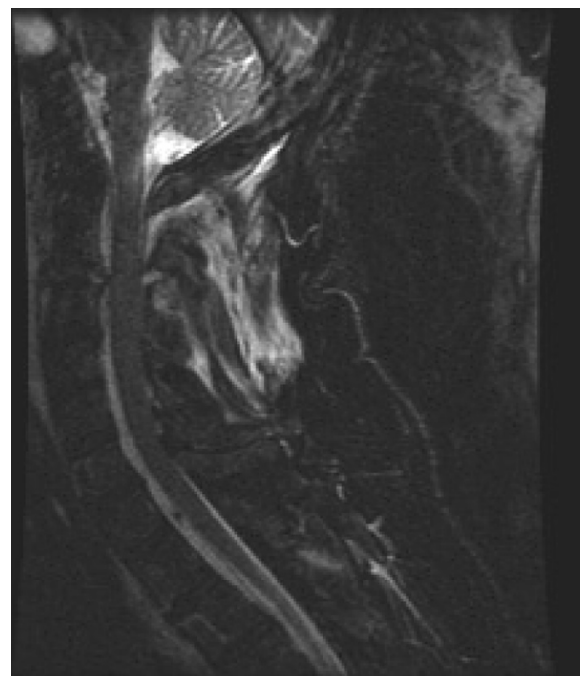

Fig. 2

Case 1 - Sagittal T2-weighted MRI scan showing increased cord signal adjacent to the fracture at $\mathrm{C} 2$.

C2-3 interspace, suggested an extension injury. His neurological examination, despite intubation, was consistent with an injury to the central spinal cord, with profound weakness of both upper limbs, but he retained gross motor activity in the lower limbs.

After two days he underwent an anterior discectomy and fusion of the level of C2-3 using a locking plate (Fig. 3) in order to stabilise the neck and to facilitate nursing care and mobilisation. He was treated in a halo vest post-operatively.

After two months, he had regained the ability to walk with assistance although he continued to suffer from profound weakness in both upper limbs. At this stage the halo was removed, but he was unable to hold his head in an

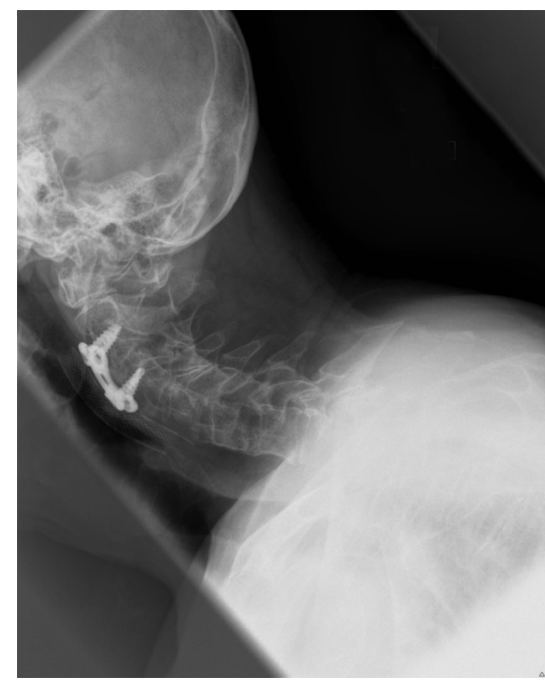

Fig. 3

Case 1 - Post-operative lateral radiograph at two years. The cervical kyphosis occurs in the lower cervical region, suggesting a proximal neurological lesion rather than local muscle injury. upright posture, and assumed a flexed position with rotation to the left.

After two years he remained unable to extend his neck fully, despite intensive rehabilitation. At his last assessment, six years after his accident, his head control had improved somewhat, although there remained profound weakness in the cervical paraspinal musculature with an inability to fully extend his neck. He has consistently declined the option of an extended posterior cervicothoracic fusion.

Case 2. A 58-year-old woman presented after being involved in a head-on collision with another vehicle. She had a comminuted type-3 odontoid fracture with disruption of the posterior ligamentous complex between $\mathrm{C} 1$ and 


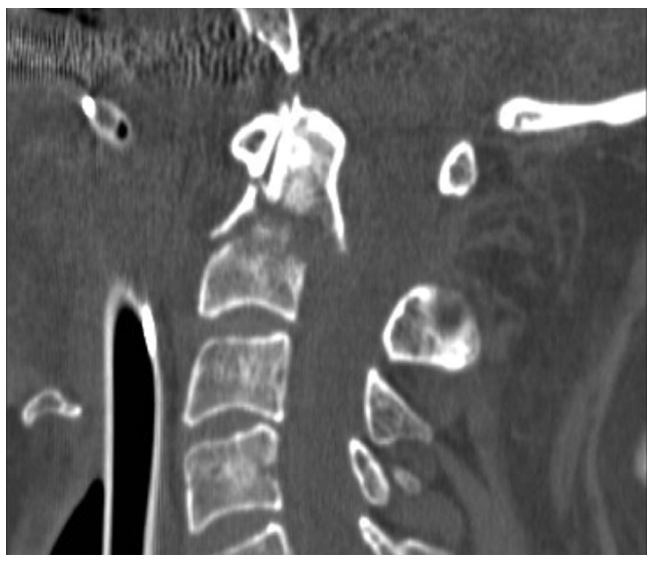

Fig. $4 \mathrm{a}$

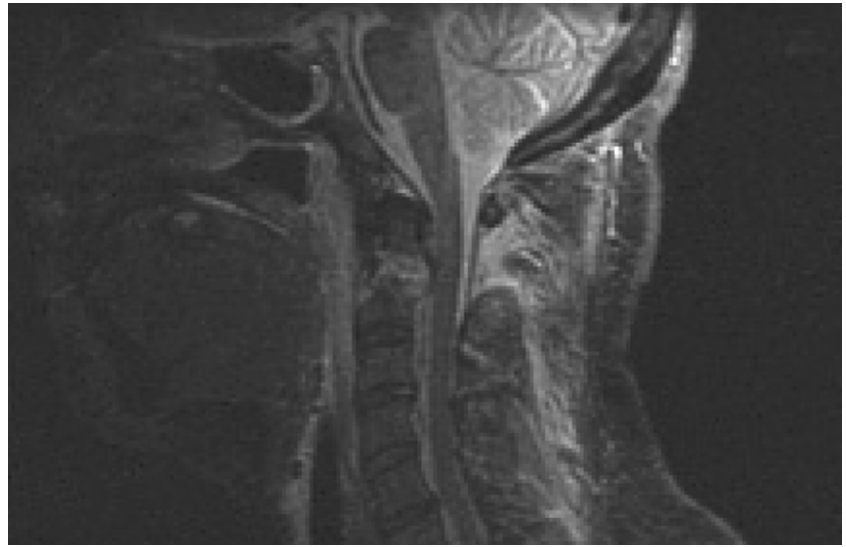

Fig. $4 b$

Case 2. Figure $4 \mathrm{a}$ - sagittal CT scan showing a displaced odontoid fracture. Figure $4 \mathrm{~b}$ - sagittal MR scan showing a displaced odontoid fracture with posterior ligamentous disruption and no increased spinal cord signal.

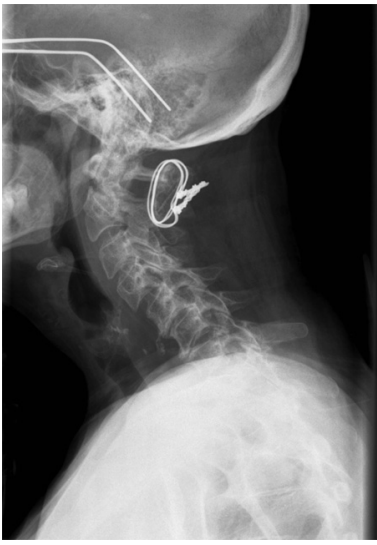

Fig. 5a

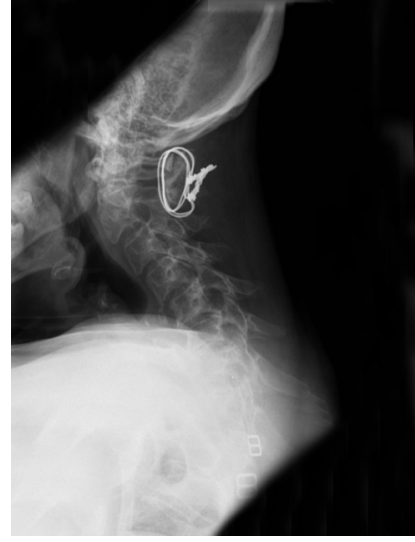

Fig. 5b

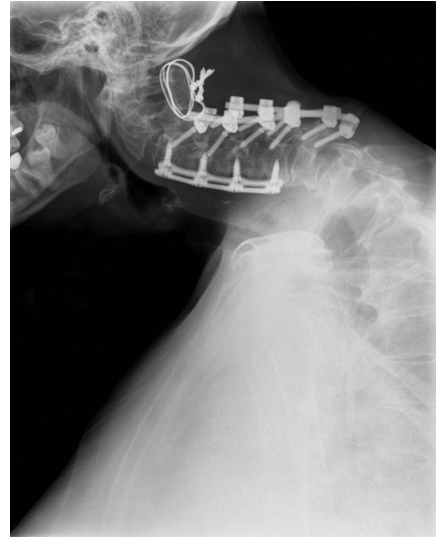

Fig. 5c

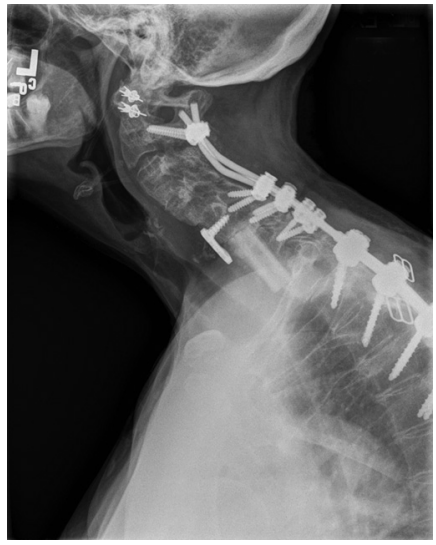

Fig. $5 d$

Case 2. Figure $5 \mathrm{a}$ - post-operative lateral radiograph after initial wiring of C1-2. Figure $5 \mathrm{~b}-$ lateral radiograph six months after $\mathrm{C} 1-2$ wiring with gradual progression of the dropped head despite paraspinal strengthening with physiotherapy. Figure $5 \mathrm{c}-$ lateral radiograph at six weeks after anteroposterior fusion showing persistence of the dropped-head position. Figure 5d - lateral radiograph six weeks after anteroposterior reconstruction from C2-T5.

C2. She was initially placed in a halo vest to stabilise the fracture during subsequent imaging.

On neurological examination she had normal power in the lower limbs and the left upper limb, but the right upper limb was weak $\left(1 / 5^{19}\right.$ in the deltoid and biceps and $4 / 5$ in the triceps and digital flexors). MRI showed an increased signal in the posterior ligamentous structures, although there was no increased signal in the spinal cord itself (Fig. 4). Five days later she underwent posterior C1-2 fusion with sublaminar wiring and iliac-crest autografting. Post-operatively, she was placed in a cervical collar (Fig. 5a). The weakness in her right upper limb slowly recovered. After removal of the cervical collar, she began to experience a tendency for her head to drop forward and to the right. Electromyography of the paracervical musculature showed an axonal sensorimotor polyneuropathy consistent with denervation as a result of injury to the spinal cord.
Despite physiotherapy aimed at strengthening her paraspinal muscles, her dropped-head position worsened (Fig. 5b). She eventually underwent a combined anteroposterior fusion from C3-6 at another centre.

No laminectomy was performed during this procedure, which failed to correct her cervicothoracic kyphosis and her problem with pain and head position persisted (Fig. 5c). After three years, she underwent an anteroposterior reconstruction with corpectomy of C6 and C7 and posterior spinal fusion with segmental instrumentation from C2-T5 (Fig. 5d). Two years later she seemed to have solid fusion with an excellent clinical result. Her neurological function in the right upper and lower limb had nearly recovered to normal.

\section{Discussion}

Schneider et $\mathrm{al}^{8}$ proposed that the mechanism of injury in central cord syndrome resulted from direct trauma followed by haemorrhage and local oedema which reduced 
blood flow to the central portion of the spinal cord. They described eight patients with a level of injury ranging from $\mathrm{C} 2$ to $\mathrm{C} 7$, and suggested that recovery was "directly proportional to the amount of edema as compared to hematomyelia, ranging from complete recovery to total destruction".

Many studies of central cord syndrome do not include patients with fractures of the cervical spinal, ${ }^{1,2,13}$ but the original description by Schneider et $\mathrm{al}^{8}$ included patients with such fractures and fracture dislocations. Merriam et a ${ }^{11}$ reported on 77 patients whom they defined as having central cord syndrome by virtue of their having greater motor involvement of the upper rather than of the lower limb. Of these patients, three had a fracture of the atlas or odontoid. However, no patient had associated weakness of the paraspinal cervical musculature.

A variety of neurological deficits and mechanisms of injury have been attributed to the central spinal cord..$^{9,13,20}$ Some authors ${ }^{21-24}$ have argued that the somatisation of the upper cervical spine in higher mammals is less organised than originally outlined by Schneider et al. ${ }^{8}$ Others have questioned whether injuries to the upper cervical spinal cord actually reflect an injury to the decussation of the pyramids (Bell's cruciate paralysis) rather than an injury to the central cord. ${ }^{10,25}$ Despite these discussions, the hallmark of injury to the central spinal cord has remained an injury to the cervical cord with disproportionate weakness in the upper limbs. ${ }^{8,9,11-14,20}$

Several anatomical studies have tried to clarify the innervation of the musculature of the posterior cervical spine. ${ }^{15,16}$ The major muscle groups which contribute to its stability and mobility consist of semispinalis capitis, semispinalis cervicis, multifidus, splenius capitis and splenius cervicis. Radicular innervation of the paraspinal cervical muscles is segmental, but typically begins cranially at the C3 root. Many anatomical texts agree that the descending motor tracts are arranged so that the fibrils which supply more proximal muscles such as the cervical musculature, are located central to those which supply the upper limbs. ${ }^{17,26}$ Assuming that the mechanism of spinal cord injury originally described by Schneider et $\mathrm{al}^{8}$ is valid, this anatomical arrangement would be expected to produce the clinical presentation of dropped-head syndrome as reported in our two patients.

While it is impossible to ascribe causation in our cases, it appears that dropped-head syndrome may be a potential consequence of injury to the central spinal cord at the upper cervical level.

No benefits in any form have been received or will be received from a commercial party related directly or indirectly to the subject of this article.

\section{References}

1. Suarez GA, Kelly JJ Jr. The dropped head syndrome. Neurology 1992;42:1625-7.

2. Oerlemans WGH, de Visser M. Dropped head syndrome and bent spine syndrome: two separate clinical entities or different manifestations of axial myopathy? J Neurol Neurosurg Psychiatry 1998;65:258-9.

3. Katz JS, Wolfe GI, Burns DK, et al. Isolated neck extensor myopathy: a common cause of dropped head syndrome. Neurology 1996;46:917-21.

4. Leung H, Hui ACF, Kay R. The dropped head. Pract Neurol 2006;6:42-3.

5. Asmark H, Eeg-Olofsson K, Johansson A, et al. Parkinsonism and neck extensor myopathy: a new syndrome or coincidental findings? Arch Neurol 2001;58:232-7.

6. Kawaguchi A, Miyamoto K, Sakaguchi Y, et al. Dropped head syndrome associated with cervical spondylotic myelopathy. J Spinal Disord Tech 2004;17:531-4.

7. Nakanishi T, Taneda M, Sumii T, Yabuuchi T, Iwakura N. Cervical myelopathy caused by dropped head syndrome: case report and review of the literature. J Neurosurg Spine 2007;6:165-8.

8. Schneider RC, Cherry G, Pantek H. The syndrome of acute central cervical spinal cord injury: with special reference to the mechanisms involved in hyperextension injuries of cervical spine. J Neurosurg 1954;11:546-77.

9. Dai L, Jia L. Acute central cervical cord injury presenting with only upper extremity involvement. Int Orthop 1997;21:380-2.

10. Inamasu J, Hori S, Ohsuga F, Aikawa N. Selective paralysis of the upper extremities after odontoid fracture: acute central cord syndrome or cruciate paralysis? Clin Neurol Neurosurg 2001;103:238-41.

11. Merriam WF, Taylor YK, Ruff SJ, McPhail MJ. A reappraisal of acute traumatic central cord syndrome. J Bone Joint Surg [Br] 1986;68-B:708-13.

12. Dickerman RD, Mittler MA, Warshaw C, Epstein JA. Spinal cord injury in a 14year-old male secondary to cervical hyperflexion with exercise. Spinal Cord 2006;44:192-5.

13. Song J, Mizuno J, Inoue T, Nakagawa H. Clinical evaluation of traumatic central cord syndrome: emphasis on clinical significance of prevertebral hyperintensity, cord compression, and intramedullary high-signal intensty on magnetic resonance imaging. Surg Neurol 2006;65:117-23.

14. Collignon F, Martin D, Lénelle J, Stevenaert A. Acute traumatic central cord syndrome: magnetic resonance imaging and clinical observation. I Neurosurg 2002;96(Suppl):29-33.

15. Zhang J, Tsuzuki N, Hirabayashi S, Saiki K, Fujita K. Surgical anatomy of the nerves and muscles in the posterior cervical spine: a guide for avoiding inadvertent nerve injuries during the posterior approach. Spine 2003;28:1379-84.

16. Bogduk N. The clinical anatomy of the cervical dorsal rami. Spine 1982;7:319-30.

17. Parke WW, Sherk HH. Normal adult anatomy. In: Sherk HH, Dunn EJ, Eismont FJ, et al, eds. The cervical spine. Second ed. Philadelphia: JB Lippincott, 1988:11-32.

18. Levine AM, Edwards CC. The management of traumatic spondylolisthesis of the axis. J Bone Joint Surg [Am] 1985;67-A:217-26.

19. Ditunno JJ, Donovan WH, Maynared FM, eds. Neurological assessment: the motor examination. In: Reference manual for the international standards for neurolog ical and functional classification of spinal cord injury. Chicago: American Spinal Injury Association, 1994.

20. Lagares A, Gómez PA, Ramos A, Alén JF, Lobato RD. Traumatic cervical central cord syndrome due to intramedullary hemorrhage studied with MRI: case presentation. Eur Spine J 2002;11:294-7.

21. Hatzakis MJ Jr, Bryce N, Marino R. Cruciate paralysis, hypothesis for injury and recovery. Spinal Cord 2000;38:120-5.

22. Hopkins A, Rudge P. Hyperpathia in the central cervical cord syndrome. J Neurol Neurosurg Psychiatry 1973;36:637-42.

23. Gillman S, Marco LA. Effects of medullary pyramidotomy in the monkey: clinical and electromyographic abnormalities. Brain 1971;94:495-514.

24. Lawrence DG, Hopkins DA. The development of motor control in the rhesus monkey: evidence concerning the role of corticomotoneural connections. Brain 1976;99:235-54.

25. Bell HS. Paralysis of both arms from injury of the upper portion of the pyramidal decussation: "cruciate paralysis". J Neurosurg 1970;33:376-80.

26. Heller JG, Pedlow FX Jr, Gill SS. Anatomy of the cervical spine. In: Clarke CR, Benzel EC, Currier BL, et al, eds. The cervical spine. Fourth ed. Philadelphia: Lippincott, Williams \& Wilkins, 2005:3-37. 